\title{
Leadership in tourist destinations' competition and its social and economic impact
}

\author{
Liudmila Belosluttceva ${ }^{1 *}$, and Olesya Fesenko ${ }^{1}$ \\ ${ }^{1}$ Sochi State University, Plastunskaya, 94A, 354000, Sochi, Russia
}

\begin{abstract}
Tourism is now more important than ever for successful, competitive and flexible destinations development. Countries actively market tourism both at national and international level. Tourism evolves and becomes recognized as an opportunity to bring wide ranging benefits to national and local economies and populations, increasingly integrated with state and destination economic planning, environment safety and community development. The analyses of the relationship between state system of regulation in tourism, administrative order and social and economic impact of constant tourism development in France - the world's leading tourist destination - is presented. The leader influences competitive advantage through developing strategy, based on traditional organizational culture and supports innovations at all organizational levels.
\end{abstract}

\section{Introduction}

France is one of the earliest countries to develop tourism and tourists flow nowadays is huge. Being the world's leading tourist destination already for years, France is ahead of Spain, the United States, China, Italy, Mexico, the UK, Turkey, Germany and Thailand. Most foreign tourists come from states close to the European Union: 55\% come from the United Kingdom, Germany, Benelux and Italy. 75\% of tourists visiting France are European. However, the number of tourists from North America remains significant: more than 3 million Americans visited France in 2017, which allowed the country to supplant the United Kingdom in this area. The number of tourists from emerging countries is constantly increasing. It is growing mainly for tourists from Latin America (increase of 20\% in 2017, thanks to the development of a middle class in Brazil), Asia (+15\%, mainly thanks to China and India), from Russia and the Middle East. The weight of tourism in France is 160 billion euros, which represents 7\% of Gross Domestic Product.

The objective of the current study was to analyze the impact of state tourism policy and administrative regulation for leadership in tourist destinations' competition and social and economic development.

\footnotetext{
*Corresponding author: belosslutzeva@hotmail.com
} 


\section{Materials and Methods}

There is no any particular EU policy for tourism, but there is environment policy, rural development policy, employment policy and transport policy which linked with tourism closely.

Ranked first world destination for years, France is particularly active in the regulation of tourism to preserve this profitable economy. State regulation at the national level is organized with the line order of tourism organizations and councils. At time when the sustainable development is perceived as a priority, state regulation is acquired for adopting measures for tourism development.

The total contribution of the travel and tourism industry to GDP in France reached around 204 billion euros in 2017 and was predicted to increase in the future. The statistic forecast for 2028 is predicted to increase up to 248 billion euros. The direct contribution of travel and tourism to GDP in France over the period from 2012 to 2018 increased reaching around 82.7 billion euros in 2017 .

The constant growth in the number of tourists brings economic and social benefits to the hosting destinations and in the same time raises the issue of the overcrowding of certain places. The resulting consequences are numerous: degradation of the natural and cultural environments, social problems, and decrease in the quality of the tourist offer, which needs the state regulation to control flow of travelers, but keeping the territory attractiveness for them.

The quality of reception is most often pointed by foreigners who "vote France, but not the French" poor command of English, remote or even arrogant inhabitants. These impressions are nevertheless strongly related to the city of Paris. Many tourists make short trips to France - a few nights only - usually in Paris. They visit some emblematic places but only cross the country as part of a longer trip. Indeed, 14 million foreigners make a transit in France, spending a simple night before leaving for Spanish seaside resorts or other countries. Some French cities are considered "dirty". France suffers more and more from an old-fashioned image of a country frozen in its past. One can also say about the factor of security: recent years France is the victim of several attacks, which can build a sense of fear.

Although the regulatory bodies most often displease the tourism industry, they are essential to ensure the sustainability of the destination implementing the state regulation.

The analysis is developed with the general international and domestic travel and tourism industry data published by World Tourism Organization (UNWTO) and numerous public and private data sources, including global travel promotion, country and industry specific organizations, databases, publications, websites, and media sources.

\section{Results}

International tourism is the world's third largest export category with 1,586 USD billion after chemicals (1,993 USD billion) and fuels (1,960 USD billion), and ahead of automotive products (1,470 USD billion) and food (1,466 USD billion) on export earnings by product category for year 2017 [1].

As countries adopt tourism as part of their economic and social value generating system, they are increasingly become interested in its development to have more share in this market by creating their own unique tourism value proposition and brand.

The geographical position of country is the first advantage: being the crossroads of tourist flows country benefits in point of tourists' arrivals even if it's counted only for single night stay. The analysis shows that it is the main reason for leading in international tourist arrivals, but not in receipts. 
In tourist destinations' competition France keeps its position of leading country for years. According the World Tourism Organization Tourism Highlights Report 2018 Edition in World's Top Tourism Destinations ranking for international tourist arrivals, 7 out of 10 top destinations are among the top in arrivals and receipts. Even between those seven destinations the rank in arrivals and receipts fits only in the case of Spain, being ranked the second in arrivals with 81,8 million of tourists and receipts with 68,0 US\$ billion. Ranked first world destination with 86,9 million of tourist arrivals in 2017, which represents nearly $9 \%$ of international tourist flow, France is ranked third in the international tourism receipts with 60,7 US\$ billion [1].

The total contribution of travel and tourism to GDP in France for last 6 years shows the increase from 197,7 billion euros in 2012 to 204,3 billion euros in 2017 (Fig.1).

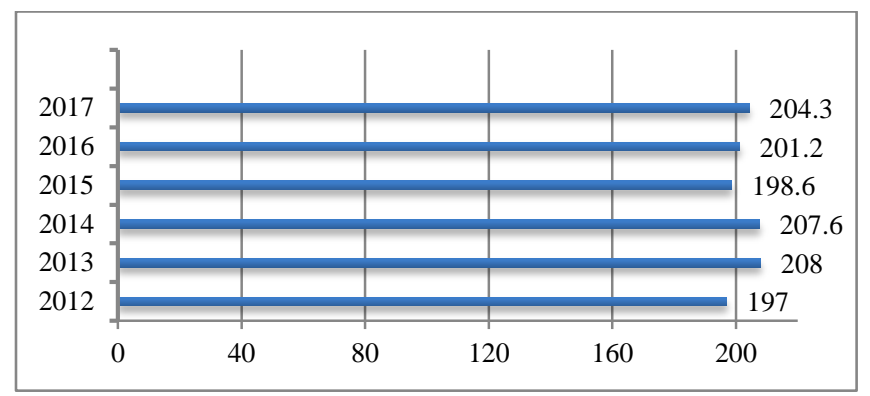

Fig.1. Total contribution of travel and tourism to GDP in France (in billion euros).

For year 2018 France keeps its leading position as first world destination with 89 million of tourist arrivals (3\% dynamics for year 2017) and keeps the third in ranking in the international tourism receipts with 67 US\$ billion [2].

The data shows that the state policy, administrative structure and regulation system in tourism altogether provide positive effect for sustainable tourism development.

The positive economic and social impact of tourism can't be shown if the communities and the environment are not well. The future of tourism is increasingly link with travelers' transformation and the connections they make during travel, including their impacts on the people and the places that they touch. Travel becomes a more meaningful two-way exchange between the travelers and the destination, instead of a one-sided consumptive and commercial transaction. This consumer evolution, along with the development of tourism, can play an important role in extenuating the negative impacts of over-tourism in popular destinations and regions.

\section{Discussions}

The geographical position of France, near the major basins emitting tourist flows, is the first advantage. Moreover, France is a true crossroads of Europe.

French regions also benefit from an ancient architectural heritage - old towns, cathedrals, monuments, and a rich cultural heritage: Versailles, the castles of the Loire, Mont Saint-Michel. Some of these sites are classified as UNESCO World Heritage sites, such as Reunion Island or the ramparts of Carcassonne.

The tourist activity in France is facilitated by a good service of the national territory by the transport network. Two international airports, Roissy and Orly, ensure the reception of a large public at the gates of Paris, first tourist destination. A network of national airports, high-speed train lines or highways ensures the service of almost all the spaces dedicated to tourism in the rest of the country. But infrastructure is also sometimes criticized: 
international airports are considered inhospitable, their service with the Paris center is expensive and impractical. It may be as important to talk about the many French "strikes", which make transport sometimes unpredictable.

In terms of accommodation, France has a dense and varied network of hotels, campsites, bed and breakfasts and rural lodgings. It also benefits from an early development of tourism: from the 19th century, luxury hotels are built on the Atlantic or Mediterranean coasts (Deauville, Cabourg, La Baule, Biarritz, Nice, Cannes). The seaside resorts and winter sports benefit from a long experience and an international reputation.

Leisure parks have also developed, attracting a considerable number of visitors. Thus, the Asterix Park, near Paris, or the Disneyland Park Paris Marne-La Vallée, the first tourist park in Europe with more than 8 million foreign visitors per year (a little over 15 million entries). The country also offers the opportunity to visit multiple animal parks, zoos, aquariums, botanical gardens.

The French way of life, the gastronomy and the wine are mentioned regularly in the surveys carried out with the tourists who chose to visit France. For example, more and more Brazilian tourists to come to France seeking above all to immerse themselves in "living in the French way", while their stays in the United States fall more, according to them, the "shopping-tourism".

Ranked first world destination for years, France is particularly active in the regulation of tourism to preserve this profitable economy.

Administratively the country is divided into 18 distinct regions, each with their own cultures and traditions. 12 are in metropolitan France, and the other 6 are the French islands around the world. The regions have an administrative capital. Each region is divided into departments, which also have an administrative capital. Lots of actors are working for the regulation of the tourism industry and its economic sustainability. They are of different natures: institutional organizations, associations or independent organizations.

State regulation at the national level is organized with the line order of tourism organizations and councils. The main governing body is Direction of Tourism, which is to develop the concept and strategy for tourism and run the activity of National Tourism Council, State Secretariat for Tourism, France house and ODIT: Observation, Development, and Tourism Engineering.

The Direction of Tourism is the organization that decided at the national level and brings together several entities. It's the decision-making body and ODIT is the one that makes the link with the regional and departmental scale.

The National Tourism Council - CNT - is the collective forum of the state with tourism stakeholders. It has the institutional form of an administrative advisory commission. Created in April 1910, this more than 100-year-old assembly is placed directly with the Minister in charge of tourism who chairs it. Its 200 members are appointed for a period of five years. The CNT brings together many personalities from the institutional, private, economic and social world or their representatives. They are parliamentarians, local authorities, the social sector, the world of employment, training and research, industry leaders, trade union leaders, or representatives of consumer associations. The National Tourism Council, through its expertise and its vocation, is able to collect information for the Minister and his services; more generally, the tourism community; the opinion, opinions, alerts and analyses of the entire sector on tourism issues in the world today. This actor is grouped in the Ministry of Economy and Finance.

The State Secretariat for Tourism is in the structure of the Ministry of the State Secretariat for Foreign Trade, Tourism Promotion and French nationals abroad. This state body aims to give the main directions to follow: welcome 100 million international tourists and 50 billion euros in tourist receipts by 2020 . 
Atout France, created in 2009, is the tourist development agency of France. Thanks to its 33 offices worldwide and close collaboration with the diplomatic network, Atout France has a detailed knowledge of the various tourist markets and distribution players. This expertise enables it to offer its 1,300 partner professional's tools for understanding demand (country and industry trends or market research) and to conduct marketing and promotional activities around destination brands. More than 2,800 promotional events are organized each year around the world, targeting professionals (international tour operators, press and influencers) as well as the general public. Atout France's mission is: to renew the offer and ensure its quality through engineering and financing for structuring tourism projects in the territories and promote the development and promotion of destination brands (and their companies) internationally.

Regional regulation is provided by the regional institutions with the following line order: Regional Prefect, Regional Delegation to Tourism, Regional Tourism Observatory, Regional Tourism Committee, Regional Council with the Department of Economy, Tourism Research and Technology.

Regional Prefect is the senior official in charge of the region, he is appointed by the President at the suggestion of the Prime Minister for a term of 3 to 5 years and forms the policy of sustainable development of the region, including tourism development.

Regional Delegation to Tourism assesses the potential of the region for foreign countries and foreign tourists. Its goal is to promote the tourism of the region, as well as to distant markets. For example, CRT participates / organizes the work of forums, tourism fairs and organizes press tours to regions for foreign journalists.

Regional Tourism Observatory provides relevant information on key themes and priorities for the development and competitiveness of regional tourism and its stakeholders. These studies inform on market trends, determine the state and innovative methods. These studies allow better adjust the future actions plans and determine the tourism development trends.

Regional Tourism Committee is a committee that develops the region tourism policy development.

Regional Council is a state body as a result of the decentralization of the French state. It is a common body that manages the region, makes decisions and distributes subsidies.

Departmental institutions of Regional Council are to design, develop and implement the regional authority decisions.

Tourism Office is an information center with the mission - "reception, information and promotion of tourism" in the territory intended for the public or visitors - from local residents to tourists. There are Tourist Offices in every tourist city around the France.

Organizations of certification are the certification bodies to make possible to regulate the tourism activities carried out in 4 main areas: the provision of hotel categories and their opening, the issue of taxi licenses, the issuance of licenses for "home-stay", official certification of tourist sites.

Atout France acts in the certification of the hotels: the hotels have to ask and fill a document to obtain certification and "stars". The comfort of the rooms, the activities, the service are analysed and after this they obtain certification every 5 years Atout France check if the stars are still in similar at the service.

$\mathrm{B} \& \mathrm{~B}$ accommodation in France by many is considered to be unfair competition to hotels, because $\mathrm{B} \& \mathrm{~B}$ do not comply with the rules of hospitality. The French state has regulated this activity: $\mathrm{B} \& \mathrm{~B}$ should offer no more than 5 rooms, including breakfast and bathroom.

The constant growth in the number of tourists raises the issue of the overcrowding of certain places. The resulting consequences are numerous: degradation of the natural and cultural environments, social problems, and decrease in the quality of the tourist offer. At 
time when the sustainable development of a destination is perceived as a priority, some actors are adopting measures to control the flow of travelers. Although they most often displease the tourism industry, they are essential to ensure the sustainability of the destination. The ecological certification is very important. In 2002, 22 ports in this region obtained a blue flag and 55 beaches were also labeled. The Secretary State of Tourism has been acted about the construction regulation on the coast, to act against the destruction of the nature for the profit of the hotel and touristic activities. They have also acted about the regulation of the website "Airbnb": lots of flats in the big cities like Paris, Nice, and Marseille are renting for the tourist and the inhabitants suffer from the lack of habitations. Actually, people to lease flats to the tourist are sanctioned.

State regulation in the field of tourism development provides the coastal construction control, environmental conditions improvement, historical monuments preservation and sustainable destination development.

There is no the EU policy particular for tourism, there are only some EU policy for environment, transport, employment and development linked with tourism industry tightly. For the employment policy, there is a harmonization of qualifications to improve the quality of service within the tourism industry through European Social Fund (ESF) to support training courses in tourism. Furthermore, rural development policy is supported by the European Agricultural Guidance and Guarantee Fund (FEOGA) for helping farmers expand their income sources and improve their farm accommodation and infrastructure to develop the rural tourism activity. The environment policy is to protect nature resources and habitats, and reduce the pollution, such as noise, air and water etc. The policy also aims to improve the environmental for better quality holiday for tourists. All these measures result the leading position of France in tourist destinations' competition with the impressive statistics numbers [3].

The direct contribution of travel and tourism to GDP in France since 2012 shows the stable positive dynamics from 80.9 billion euros in 2012 to 82.7 billion euros in 2017 (Fig.2).

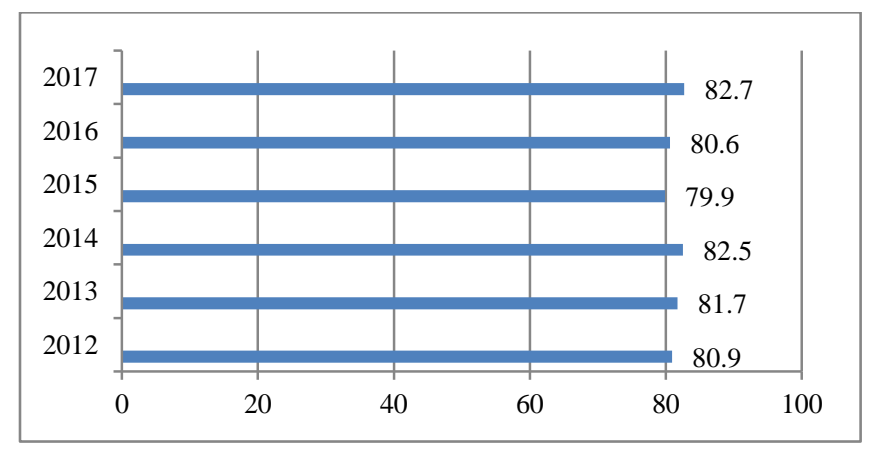

Fig.2. Direct contribution of travel and tourism to GDP in France (in billion euros).

Travel and tourism directly contributed to employment by generating approximately 1.19 million jobs in France in 2017, when totally contributed approximately 2.8 billion jobs to the country's economy. The statistical data is presented in Fig.3 and Fig.4. 


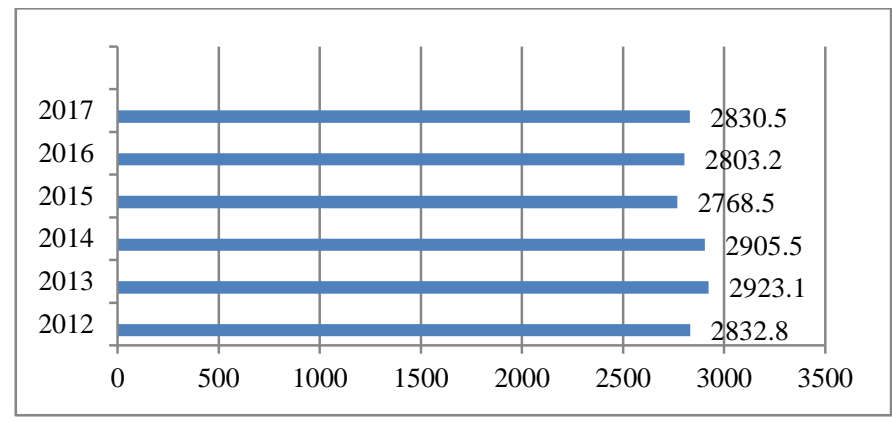

Fig.3. Total contribution of travel and tourism to employment in France (in million jobs).

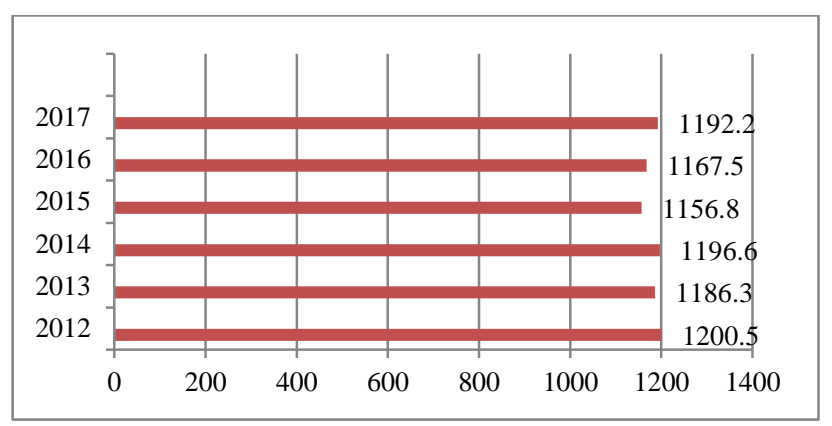

Fig.4. Direct contribution of travel and tourism to employment in France (in 1000 jobs).

Direct contribution to employment is a status measure for the travel and tourism goal. To count it the data from the World Travel and Tourism Council (WTTC) on direct employment in the tourism and recreation sector (hotels, airports, airlines, travel agents and leisure and recreation services that deal directly with tourists) as an indicator of the number of travel people is used. Data from the World Bank and the World Travel and Tourism Council (WTTC) are used to compute the proportion of the total labor force (corrected for unemployment) in each region that is directly employed in the travel and tourism industry. This method assumes that the number of employees in hotels, travel agencies and other affiliated professions will increase or decrease with changing tourism demand - both international and domestic - within different countries and regions. The proportion or people working in the tourism sector is then multiplied by a sustainability factor derived from the Travel and Tourism Competitive Index (TTCI) to yield the region's status score for Tourism \& Recreation. The reference point is for the proportion of people employed in a region's tourism sector to not decrease over time [4].

The annual value of visitor exports or international tourist spending in France (leisure and business travel spending by international tourists) was estimated to reach a value of 46.2 billion euros in 2018. Domestic expenditure is estimated to reach 114.9 billion euros in 2018, up from spending in 2017. Spending of domestic tourists more than doubled that of international tourists, although both are forecast to increase until 2028. 


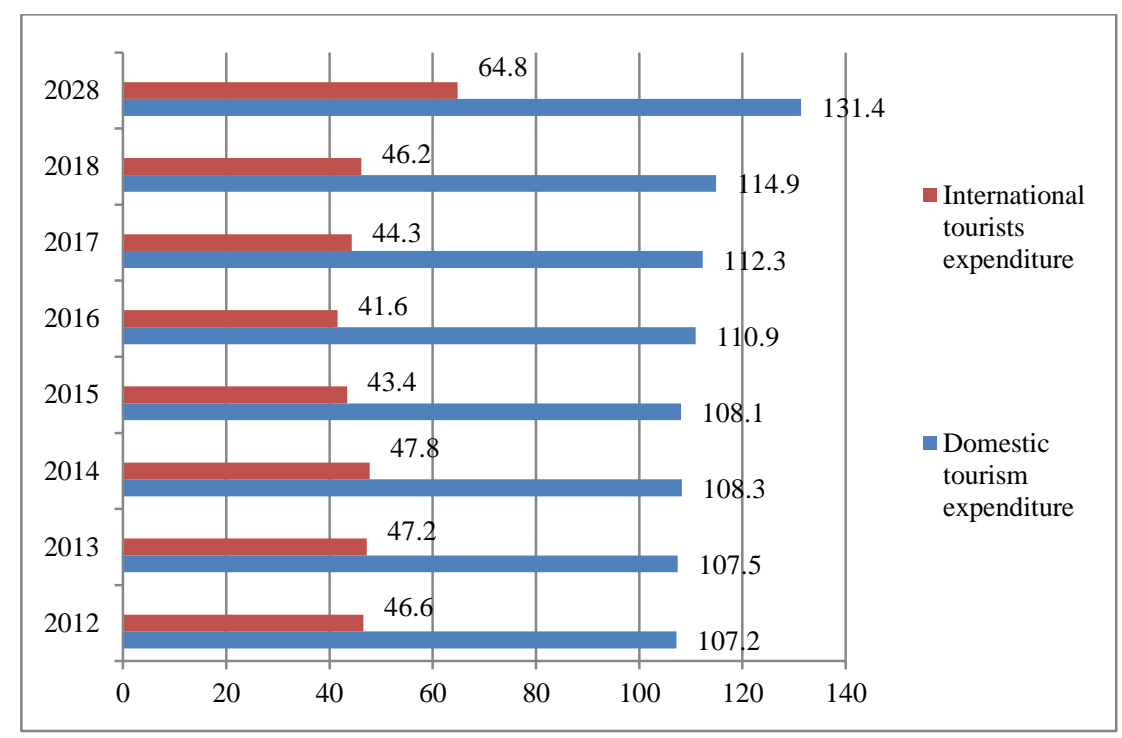

Fig.5. Annual value of international and domestic tourist spending in France, including the forecast for 2018 and long-term perspective for 2028 (in billion euros).

Domestic expenditure considerable is estimated to reach 114.9 billion euros in 2018, up from spending in 2017. Spending of domestic tourists more than doubled.

\section{Conclusions}

Despite occasional economic shocks, tourism demonstrates sustained growth. Tourism sector's strength and flexibility are proved by $5 \%$ growth in total international tourist arrivals (1.4 billion) and $4 \%$ growth in total international tourism exports, including international tourism receipts and passenger transport (1.7 USD trillion). The revenues from visitor spending have grown faster than the world economy with 5,5\% change in real terms in receipts in comparisons to $3,8 \%$ growth of GNP for year 2017, and 4,4\% receipts growth against 3,6\% GNP growth for year 2018.

Ranked first world destination for years, France is particularly active in regulation of tourism to preserve this profitable economy. The competitive tourism environment encourages country to efficiently develop strategy, based on traditional organizational culture and innovations at all organizational levels.

Although the geographical position of country and cultural heritage is considered the main advantage, regulation system is found to be one of the key elements of business success in tourism concerning the leadership data in tourism industry. Practical values for leadership management in tourism are that they are forced to mediate through expansion of advanced, adaptive, flexible measures to develop business models that would give the competitive advantage. With the traditional concept of the administrative line order of tourism organizations and councils at the national level France creates opportunity to try new ideas without risk of major change of tourism model.

Local experience acquirement is considered nowadays as one of the main tourist trends. Nowadays tourists don't want to be visitors to see the tourists' attractions, they want to be engaged and participate in the local culture. From enjoying local cuisine to celebrating festivals and holidays, local experiences are set to become of the top tourist trends. Always being focused on own way of lifestyle, France created its own unique promotional profile 
for all the other world desire to try "living in the French way" and discover it throughout the tourist's experience.

According Eurostat "Arrivals of tourists at the border refers to the number of international visitors who arrive during a given year in a given country and who are staying at least one night..." [5]. The leading position of France in international tourists' arrivals is stipulated by significant number of one-night stay. That is the reason that France is only third in numbers of tourism receipts. But the analysis done, show that domestic tourists' expenditure more than doubled that of international tourists, with both are forecast to increase until 2028 [6].

The share of France in the Europe international tourism receipts for year 2018 is $11,8 \%$ with share of international tourism arrivals 12,6\%, that ranked France the first for international tourism arrivals and second for international tourism receipts.

With the total growth of tourists flow by 5\%, and impressive growth for Asia and the Pacific region and Africa region by $7 \%$ both, the Europe with 5\% growth demonstrate $51 \%$ share in international tourist arrivals and $39 \%$ of international tourism receipts for year 2018 results, being the world's most visited region and promising more successful years in a row of sustained growth [7-9].

\section{References}

1. F. Valentea, D. Dredgeb, G. Gui Lohmann, J. Destin. Mark. Manag 4(2), 127-136 (2015)

2. D. Joo, H. Cho, K. Woosnam, Tour. Manag. Persp. 31, 231-235 (2019)

3. G. Croucha Del, R. Chiappa, G. Perdued, Tour. Manag. Persp. 71, 530-542 (2019)

4. A. Monje Amor, J. Vázquez, J. Faíña, Eu. Manag. J. (2019) DOI: 10.1016/j.emj.2019.06.007

5. K. Vodeb, Proce. - Soc. Beha. Sci. 44, 273-278 (2012) DOI: 10.1016/j.sbspro.2012.05.030

6. M. Testa, L. Sipe, Int. J. Hospit. Manag. 31(3), 648-658 (2012)

7. S. Shafieea, A. Ghatari, A. Hasanzadeh, S. Jahanyanc, Touri. Manag. Perspect. 31, 287-300 (July 2019)

8. T. Nguyena, T. Younga, P. Johnson, S. Wearing, Touri. Manag. Perspect. 32 (2019) DOI: $10.1016 /$ j.tmp.2019.100575

9. B. McKercher, B. Mak, The impact of distance on international tourism demand Touri. Manag. Perspect. 31, 340-347 (July 2019) 